\title{
PREPRINT
}

To Appear in Int. J. Human Resources Development and Management, Vol. 4, No. 1, 2004. p. 73-93

\section{WAW - an Activity Theory Based Tool for Early Website Usability Assessment}

\author{
Dr. Olav W. Bertelsen \& Mikkel Godsk \\ Department of Computer Science \& IT-University West, University of Aarhus \\ Aabogade 34, DK-8200 Aarhus N, Denmark \\ \{olavb,godsk\}@daimi.au.dk
}

\begin{abstract}
In recent years there has been a growing interest in ways to use activity theory as a tool for understanding computer applications in context. The work in this field has primarily focused on how to understand computer applications in a current work practice and how to improve existing computer applications. At the same time methods for website inspection have been very pragmatic and theoretic. In this paper we present an activity theory based tool for early website usability assessment called Web site Activity Walkthrough (WAW). WAW is an attempt to build a cheap and effective tool for early, formative usability inspection based on activity theory.
\end{abstract}

Keywords: website activity walkthrough, activity theory, web usability inspection, WAW.

\section{INTRODUCTION}

For some years activity theory has gained increasing attention in the HCI community, mostly as a conceptual framework emphasizing aspects such as context, mediation and development. However, when it comes to practical tools for interface design and assessment, only few contributions have been made, e.g. focus shift analysis [6] and the activity checklist [11].

Ideally, techniques for early assessment of the usability of a computer application should be made before the system is implemented. Mock-ups and prototypes are well known methods for involving users in the assessment before design, whereas purely analytic methods like heuristic evaluation [14] and cognitive walkthrough [13] bypass the need for users, letting the designer do the assessment himself. From the point of view of activity theory, we might argue that such analytic methods are too limited, that they will never capture the richness of the real world, and that the involvement of real users doing real work is indispensable [1]. From the perspective of practical design, however, we might argue that we need all the tools we can get even if they are approximate and incomplete. In particular we need cost effective tools, such as analytic methods helping designers stay on track and pruning out as many usability problems as possible during early design.

The cognitive walkthrough is popular and widespread due to its simplicity, and possibly because the inspector does not need to know a lot about the underlying theory of exploratory learning. All s/he needs is to identify some typical tasks and break these tasks down to a sequence of steps. For each step, s/he then judges if the appropriate action is obvious to the user, if the user can connect the correct action to the desired outcome, and finally if the user will get appropriate feedback [13]. The hard part of applying this method, however, is related to the fact that the method does not directly provide help in understanding tasks within concrete, relevant contexts.

The analytic tool proposed in this paper is an attempt to make an operational technique for early (analytical) assessment based on activity theory. We try to overcome the dilemma between conceptual frameworks not lending themselves to operational instruments, and operational approaches reducing their theoretical basis too much; as well as the dilemma between sensitivity to the real world complexity and the cost effectiveness of purely analytic methods. We do this within in the special case of a method for website walkthrough called the Web site Activity Walkthrough (WAW). In WAW, an elaborate checklist specially fitted to the World Wide Web is used. In initial experiments with WAW, the method 
has been used for evaluating an early version of a site presenting a new type of IT education to prospective students, the industry, the press, etc.

The fact that the WAW is a purely analytic method violates the basic tenet of activity theory to always ground analysis in empirical studies. In the development of WAW it has been a general challenge to balance between exegetic theorizing and careless eclecticism. We believe that we have been able to strike a fruitful balance between these two extremes in our attempt to bring activity theory to practical usability work.

The Web site Activity Walkthrough (figure 1) is composed of two parts. Firstly the website is situated in use and relevant use situations are identified (step 1). Secondly, each use situation is broken down into a sequence of actions; each action is inspected (step 2) and solutions to identified problems are outlined (step $2 \& 3$ )

INSERT FIG 1: The website activity walkthrough

\section{ACTIVITY THEORY}

The basic unit of analysis in activity theory is human activity (e.g. work), that is, the endeavor of a group of people to realize some object. Activity is socially mediated by artefacts, i.e. division of labor, rules, social formations, language and instruments, e.g. [1, 2, 3, 7, 10]. Kaptelinin [10] summarizes the six most important aspects of activity theory in the context of human computer interaction as: the unity of consciousness and activity, object orientedness, the hierarchical structure of activity, internalization/externalization, mediation and development. Computer artefacts and websites, like all other artefacts, mediate human activity within a practice. Human beings meet the objective world through outward acts. Thus, human knowledge and experience about the world is reflection obtained through activity, forming the basis for expectations and desires about possible activities. Human activity can be analyzed as a three level hierarchy: activities are realized through chains of actions, which are carried out through operations (see figure 2).

INSERT FIG 2: The hierarchical structure of activity

At each of these levels the objective world is reflected through the activity. Human activity is always directed toward a material or ideal object satisfying a need. The subject's reflection of and expectation to this object characterizes the motive of the activity. Human activity is carried out through actions controlled by the subject's conscious goals. Goals are the reflection of the objective results of the action. Actions are realized through a series of operations; each determined by the concrete physical conditions of the action. These operations are performed without thinking consciously but are oriented in the world by a non-conscious orienting basis of the operation. This orienting basis is established through experience with the concrete material conditions for the operation, and is a system of expectations about the execution of each operation controlling the operation in the process of the activity [12]. Engeström depicts human activity as a triangular systemic structure saturated with contradictions both internally (figure 3) and in its relation to its neighboring activity systems [7].

INSERT FIG 3: The systemic structure of activity

Contradiction is a basic, inevitable feature of an activity system and the basic source of development (for an example of the analytical power of the concept of contradiction see e.g. [4]). Primary contradictions are inside each corner of the activity. The secondary contradictions are contradictions between corners in the activity triangle: e.g. between the instrument used and the object of the activity. Tertiary contradictions are those between the considered activity and what it could possibly develop into. The 
quaternary contradictions are those between the activity system looked at and neighboring activities: e.g. between the IT-university (the considered activity) educating candidates to match the academic criteria and the IT industry (the activity consuming the products) needing to hire employees with skills enabling them to fill open jobs immediately. In the WAW we are mostly concerned with what Engeström [7] describes as secondary and to some extend quaternary contradictions.

Computer applications and websites mediate human activity. According to Bødker [5] computer applications mediate use in three different ways: as being a system, a tool or a medium. Ideally, a tool is transparent (i.e. not in focus) in mediating the users shaping of some material. A medium is transparent in mediating the communicative relation between human beings. A system is not transparent to the user because the purpose of the system is placed outside the use context.

The activity theory framework has gained increasing attention as a conceptual basis for HCI and related disciplines. However, the framework basically rely on a sensitivity to the specifics of the studied domain, concrete empirical studies, etc. As pointed out by Engeström:

"Activity theory is not a specific theory of a particular domain, and does not offer ready-made techniques and procedures. It is a general interdisciplinary approach, offering conceptual tools and methodological principles, which have to be concretized according to the specific nature of the object under scrutiny" [8 p.97].

Thus, the specifics of the domain of interest should be included in the analysis to benefit from the general framework. In the WAW we have incorporated knowledge about the specifics of web-technology and the culture of web-design to be concretized in the general framework.

\section{BASIC PRINCIPLES OF THE WAW}

The WAW is an attempt to make a tool based on activity theory to identify problems with and in connection with websites. The main idea of WAW is to contextualize the uses of a website into possible use situations using basic principles of activity theory. These possible use situations can then stepwise be inspected for potential problems, and because WAW uses the activity theoretical framework to understand the use of a website as a whole, the identified problems may concern the use context as well as the specific interface design of the website. The core of WAW is derived from the checklist used for situating computer applications in use before doing focus shift analysis on video data [6].

WAW consists of three parts. First the website is described and situated, secondly problems are identified, and finally, it deals with the identified problems.

The first part, the preliminary work in describing and situating the website and its users, consists of an identification and contextualization of uses into possible use situations according to the design specification. The second part identifies the problems, and is worked out as a walkthrough where the possible use situations are analyzed and problems with their underlying contradictions are identified. Depending on the nature of the identified problems, the problem is solved immediately in part two or just described so that further problem solving and/or follow-up is possible in part three.

\section{p79 DESCRIBING AND SITUATING THE WEB SITE}

The starting point in performing a test is to identify and categorize uses of the website. To identify the uses is a matter of realizing which uses the website may be a part of depending on the uses the website must support. The website may have several uses with varying importance, and WAW uses this importance to help the inspector find the right solution to the identified problems.

WAW distinguishes between four kinds of uses - all of various importance (see step 1.1, figure 1):

- Necessary uses. Uses that the website must support to fulfill its purpose/to justify its existence. E.g. an online bookshop must support users in buying books - otherwise the site is useless!

- Frequent uses. Uses that are not directly "necessary", but probably will be frequent. It is often a political (and economical) question to which extend the website shall support these uses. 
- Extra-ordinary uses. Based on the inspector's prior knowledge about similar websites, or a close analysis of the assumptions in the specification it may possibly be foreseen that users will use the website to achieve objects of necessary or frequent use in other ways than intended in the specification.

- Other uses. The inspector should consider use not covered by the three categories.

\section{Putting uses into context - "contextualization"}

The specified uses must then be put into a bigger context so the possible use situations can be identified, in line with [6], we use the term contextualization.

Several authors have shown that a computer application can be contextualized along several dimensions (or basic "principles") of activity theory [6, 10]. These dimensions are most often derived from Engeström's work [7], and typically focus on understanding the use of the application.

As a starting point in our work on developing WAW, we adapted the contextualization dimensions from Bødker's focus shift analysis [6] by combining them with Kaptelinin's use perspectives and basic principles of activity theory $[10,11]$. We thus obtained a number of contextualization dimensions. Combining these dimensions with general characteristics of websites (as described e.g. in [15]) we got the contextualization dimensions listed below. Initial tests showed that these basic contextualization dimensions were relevant in contextualizing the uses of a website and that the dimensions did benefit by including the characteristics of websites. The initial tests also showed that the initial contextualization dimensions were not adequate alone.

\section{The distribution dimension}

The examples in $[6,10,11]$ included applications which could be observed/understood in a certain context with certain rules, division of labor etc. However, the contextual components about division of labor, the community or the rules are hard to describe because of the characteristic distribution of websites. A website is most often used simultaneously in several contexts: the local context of the user, the context of the internet or the context of the website. Because all these contexts have different characteristics, we introduce the "distribution" dimension in order to distinguish between local, internet in general and website contexts.

\section{The contextualization dimensions}

The first contextualization dimension is about understanding the website and its future use. This understanding is established by combining explicit and implicit assumptions about users, future uses, content and purpose of the website. This dimension may be compared to a design specification where the basic characteristics of a website are described in gross terms.

The second dimension is about situating the website and its uses. This dimension examines experiences with the existing website (if any), how the design is substantiated, and how the new design will influence existing work etc. This dimension is especially interesting if the website has a history - is it an improvement of an earlier version, a redesign or a completely new site? But if it has not, additional websites with an equal purpose, use or users may have a history of interest. If e.g. the website is an online email service, it might be necessary to include specific knowledge about the use of email and studies of similar services.

The next step is to understand the mediation of the website; the connection between user, website, other users and/or the objects. The website, in its various uses, is characterized as being system, tool and/or medium. All three mediations are possible on websites in various combinations, but currently a tool mediating website is rare. Typically websites can be understood according to the system- or mediumperspective. To paraphrase, this dimension is about understanding.

The website may also be characterized according to the principle of internalization and externalization. This dimension comprises an assessment of how the website supports learning and development in use. 
How does the website support the user in transforming conscious actions with or on the website into unconscious operations? In the opposite direction, how does the website support the users unloading of mental effort to the website, e.g. by providing advanced features for formulation and storage of complicated search strategies?

The last of the initially dimensions is situating the website in its network of activities and identifies in which activities the website take part and how these activities are related. The main purpose of this dimension is to create sensitivity to the networks of activities rather than to make a complete and specific analysis. The website is not the only instrument the user will interact with, and in many situations the website will be shared between different activities, serving different purposes. Motives of potential activities are recognized by asking why the website is used by the (various) users in order to do something.

Web sites are both part of the World Wide Web in general and subject to local use. The distribution dimension focuses on the context of the website by a distinction between local context, internet context and website context. The local context of the website will in most cases be a regular activity system. Consider a secretary using a travel website to order the best ticket for a business travel of service technicians'. The local context is the company with its division of labor between secretaries and technicians, rules regulating travel expenses, etc. In the analysis of rules, community and division of labor of the local context, the inspector may need special tools, adapted from other sciences - e.g. marketing or organizational analysis. The internet context of the website is not an activity system, but rather the culturally, and techno-historically developed basis for the website. When the secretary uses the travel website, she is able to interact with and through it because it triggers her web-specific orientation basis; and she depends on a certain level of trust, based on general experience with e-commerce, when she purchases the ticket on-line. In describing the internet context the evaluator might analyze related websites to get an understanding of the established cultural norms and standards and how they influence users' expectations. The website context is, the socio-cultural room constituted by the site and the actions of the people interacting with and through it. In some cases an on-line community emerges "on" the website, being more or less ephemeral, ranging from regular activity systems to something better described as accidental meetings or what Engeström describes as knot-working. In all cases, users "go into" the room defined by the website, and the success of their encounter with the site depends on their ability to align themselves with the "cultural norms" of that place. The secretary goes into the website to book the travel; she understands that it is not possible to negotiate prices and book hotel rooms at the travel website. The travel website might also offer an on-line forum for regular costumers, here the secretary check the list of hotels recommended by other members, and when she does not find what she needs, she posts a question in the discussion room. The three contexts of the website will be of variable importance depending on the purpose and structure of the considered site.

\section{Possible use situations}

By contextualizing according to the described dimensions, the inspector should have a sufficient impression of the activities that includes the website. Since WAW is intended for analyzing a not yet existing website, defining possible use situations may not, depending on the contextualization, be done completely. Adequate information about users, objects, design, mediation etc. makes a more accurate contextualization. In other words, it is easier to define possible use situations of websites with a limited, well defined and homogeneous target group and a few purposes.

Defining possible use situations is done by combining the specified uses and the contextualization. In practice, the inspector considers the motives underlying each specified use according to the hierarchical structure of activities by asking "why?". It is important that the answer (the possible use situation) is substantiated by the contextualization.

The answer to the questions combined with the contextualization is then used to outline the possible use situations according to Engeström's activity system triangle. These triangles are then used for the problem identification. 


\section{IDENTIFYING PROBLEMS AND SOLUTIONS}

Identification of problems in WAW is designed as a walkthrough. By stepwise analyzing the possible use situations, potential problems are identified. The inspection of each possible use situation is carried out by outlining the systemic structure (the activity triangle) of the activity [7] (see figure 2) and analyzing the involved contradictions, to identify problematic ones. If any contradictions immediately appear to cause problems, the inspector examines the use situation for possible solutions that do not introduce new contradictions, and the solution is described. If the inspector cannot find any possible solution, characteristics about the contradiction and the problems it causes are described for later follow-up. After this, the use situation is inspected stepwise, action by action, the same way. If an action is unproblematic, the inspector continues to the next action.

When all possible use situations are inspected, the inspector has described the solutions to a number of problems and furthermore characterized the causes to another number of problems. Depending on the characteristics of problems a solution is decided:

- Ignoring the problem. If e.g. the use that caused the problem has a low importance (extra-ordinary or less frequent).

- Changing the design of the website. If a problem can be solved immediately by changing a few components and this does not introduce new contradictions, this might be the right solution.

- Modifying the design specification. If it is a major problem or the problem can not be solved by changing the design and the use is "necessary", the problem might be prevented by modifying the specifications of users, target groups, purpose etc.

- Testing the problem. A problem might not be that actual or as important as first assumed. If doubt arises, consider performing an empirical investigation of the issue.

When the problems are solved and/or the specifications of the design and use of the website are revised, the design may begin.

\section{HOW TO USE WAW}

WAW is an analytical design tool, which in this case means that it is designed for early and formative website usability assessment of websites not yet existing, thus it is intended to be used without the final product or even a prototype. Nevertheless WAW requires reasonable and sufficient design specifications and assumptions about target groups, uses, purposes and design. By "sufficient specifications and assumptions" we mean information enough to specify the uses of the website and to contextualize these uses into possible use situations.

"Sufficient specifications and assumptions" is variable, depending on the aim of the inspection (e.g. how specific the inspector wants the identified problems to be) and the characteristics of the website. Typically, WAW would at least require information about the purpose of the website (necessary uses), the history of the website, the characteristics of major target groups and a number of different characteristics of the website - e.g. the contents in great terms, the interface design, information structure etc. Since the process of using WAW shall be considered dynamic, WAW may show additional requirements for information during the process. E.g. WAW may identify a possible contradiction between the division of labor of the user's context and the structure of the information on the website. In this case the inspector may need to gather additional information about these matters that were not initially considered "reasonable".

p83 The typical procedure for WAW based inspection consists of the following major parts:

- Clarifying the requirements for the website: definition of users, purposes, contents and design of the website. This may not be the inspector's job. In many cases a requirement specification is the given starting point drawn up by the originators of the website.

- Understanding the case and acquiring additional information. It is important that the inspector understands the case very precisely. This may be ensured through case descriptions or future scenarios 
concretizing the use of the new website. This may lead the inspector to search for additional information to clarify specific issues.

- Performing the WAW. When enough information has been collected, the WAW may begin. During the process it may be necessary to collect more information.

- Subsequently the identified problems and their solutions are listed. If the solutions to identified problems require major changes in the design specification, a new WAW may be needed. Otherwise the identified solutions are used for the design process to follow.

- Inspection during design. WAW is used for iterative analysis of contradictions. If any component changes, the designers (or the inspector) should look for new contradictions and consider the consequences. Major contradictions may require a new WAW of the current design.

\section{AN EXAMPLE OF WAW IN USE}

To illustrate the flow of the WAW in use, we present a condensed version of the analysis of a specific website currently being developed. The example focuses on the definition of uses and use situations, the problem identification and the identification of solutions.

The website in question is a redesign of a previous and rather similar website that represents various IT educations to prospective students and the IT industry. Because of new demands and expectations to design and contents, the previous website had to be redesigned. The new design is required to be more representative of the curriculum and professional level of the educations, and it is hoped to convey a positive image of the graduates to future employers in the industry. The site should include information about the qualifications the students acquire, job opportunities, study environment and facilities etc.

\section{Step 1.1: Identifying the uses}

The first step is to identify and categorize the uses of the website. In accordance with the description above, the following necessary, frequent and extra-ordinary uses were identified:

p84 Necessary uses:

- To convey a positive image of the professional level and the qualifications of the students to the IT industry and future students.

- To provide information about the educations, study environment, future occupation, contact persons etc. for future students.

Frequent uses:

- As a reference for current students applying for job.

- For other target groups, e.g. the press, other universities etc., to obtain various information.

Extra-ordinary uses:

- Enrolled students may try to use the website to find information about specific rules e.g. concerning exams.

\section{Step 1.2: Contextualization}

I order to identify possible use situations, the identified uses need to be contextualized. This is done by considering the questions in WAW, step 1.2.

The website and its future use may be understood according to a number of purposes; to attract future students, to inform future students about the educations, study environment and future occupation, to convey a positive impression of the students to the IT industry etc. Preferably communicated by a creative, appealing and usable website with a relevant and serious content.

The website is situated as a combined redesign and further development of an existing website. The existing website was primarily designed for future students, but it does not provide sufficient information about study environment, admission procedures, start of studies and later job opportunities, consequently, the website was not really used. Ideally the website would provide answers to frequent asked 
questions, e.g. about studies or study environment, thereby making it unnecessary for future students to contact the education supervisor or visit the university. Furthermore the website should be expanded to target the IT industry.

The mediation of the website is primarily media-like. The site is a medium for communicating between the IT University and its prospective students, employers of candidates and the general public; and specifically between students and employers. A tool-like mediation occurs when the website supports recruiting officers' work on the student database understood as material, e.g. when it is providing means for building specific student search profiles. System-like mediation should ideally be avoided in this kind of website, as it means that users have to perform actions not motivated within their own activity. However, system-like mediation cannot be completely avoided when it comes to user registration and login, and it might be necessary to force students to engage in system interaction to ensure consistence and completeness of the student database.

On the website, support for internalization is primarily ensured by conformance to standards and visibility of novel possibilities. Since the site is not used on a daily basis by most of the users there is no point in putting a lot of effort into the development of non-standard features and interaction forms. $E x$ ternalization might be supported by features of the website for formalizing and refining e.g. search profiles as part of the above described tool mediation

Since students, teachers, administration, the press and other universities may all have individual motives for using the website, the complete network of activities is difficult to identify. As described in step 1.1, the website must support future students in finding information about studies, study environment etc., and the IT industry in getting a positive impression of the professional level of the students, so activities involving or influencing these uses must be taken into consideration. Other activities may involve the website, but probably will not have any influence on the activities including necessary uses.

The distribution of the website can be considered as local, and partly as internet. The user may typically use the website within a local context where the local rules, community and division of labor influence the use situation. If the user often visits recruitment websites or compares the content of the website with other similar websites, the rules and community of the internet context may influence the use situation.

\section{Step 1.3: Identifying possible use situations}

By combining information about the target group and the use of the first identified necessary use, it is possible to formulate the following question:

\section{Why does the IT industry use the website to create an impression of the professional level of the students?}

In accordance with the contextualization the answer to this question identifies the use situation (use situation \#1) as:

The IT industry uses the website to examine the possibilities for acquiring qualified labor in an easy way to solve a scarcity of labor and/or to improve the productivity etc.

A complete inspection of a website repeats this identification of use situations for each identified use (in step 1.1), but in this condensed example we will only focus on the just identified use situation.

In accordance with the contextualization of the use and the identified use situation, it is possible to identify the following instrument, subject, object and outcome of use situation \#1.

- Subject: The user from the IT industry.

- Object: Various information about the qualifications and professional level of the students.

- Outcome: Employment of the right, qualified students.

- Instrument: The website, the user's (from the IT industry) intuition, preferences and experiences from corresponding websites etc.

Taking the characteristics about the distribution of the website into consideration, the rules and community must be understood in a combined local and internet context. The company may e.g. have adjusted 
the rules and procedures of recruiting new employees to how it works on the internet. This leads to the following components:

- Rules: Procedures of hiring at the company and how it works on the internet in general. Usual ways to get employees via the internet is by recruitment websites where companies place job adverts, by databases with CV's and profiles of people, or by $\mathrm{CV}$ databases at the recruiting companies.

- Community: Primarily, the community of the people hiring new employees at the company, and secondarily, the IT industry, the company in general and the internet.

- Division of labor: Identifying the scarcity of new labor, searching for new employees, hiring and job interviews may be done by the same or different persons in the company.

When the components of the considered activity are identified (object, subject, instrument etc.), it is possible to outline Engeström's triangle of the use situation (figure 4).

INSERT FIG 4: The activity system containing use situation \#1

This triangle is used in step 2 to identify problems, but first, we have to identify a reasonable action sequence of the use situation. We do this by considering the identified use situation. Since the IT industry uses the website to "solve a scarcity of labor", the initial step must be to identify the scarcity of labor, and afterwards to get the idea of looking to the internet for labor and acquiring the address of the website. When the user enters the website, the website will be used to "examine the possibilities [...] in an easy way", so the ideal use of the website could be described in three steps - initially searching for information, secondly selecting the students and finally contacting the students. If the company has contacted one or more students, the next step would probably be a job interview and maybe employment.

p87 So the complete action sequence of the use situation would probably be the following:

1. Identifying a (possibly) scarcity of labor.

2. Getting the idea to search the internet for labor.

3. Acquiring the address to the website.

4. Searching the website.*

5. Acquiring information about students.*

6. Selecting the students.*

7. Contacting the students.*

8. Job interview.

9. Employment of the right students.

* These steps involve the website

\section{Step 2: Identifying problems}

The Engeström triangle (figure 4) and the listed action sequence is the basis for the problem identification by analyzing the contradictions of the activity triangle. Before walking through the action sequence, the contradictions of the triangle are analyzed; two contradictions immediately seem problematic:

1. The contradiction between the procedures of hiring (the rules) and the website (the instrument); since the company usually employs labor through announcements - no headhunting! A solution could be to change the appeal of the website or letting the companies announce job openings.

2. The contradiction between representing the students in text and graphics (the object) and craving for means for meeting the whole person face to face (the subject). No immediate solution could be pointed out.

After the immediate problem identification is done, the use situation is inspected action by action: 
Action \#1-3: The three initial actions do not involve the website - we will ignore these actions in this condensed example.

Action \#4: This action does not show any immediate contradictions, but draws attention to how the information is structured on the website in relation to how information about personal qualifications is structured in the industry and on recruitment websites (i.e. related to the whole network of activities).

Action \#5: Acquiring information about the students includes a contradiction between the data about the students on the website (object) and the usual design of a job proposal or what the user wants to know (subject). This may immediately be solved by either adding more information about the students (but this may cause other contradictions to other specifications of the website) or adding an email address, so the user may contact the student and obtain the needed information.

p88 Action \#6: Selecting the students may contain a contradiction between how different people usually are involved in hiring new employees (division of labor) and what instruments the website offers (instrument). If usually different people at the company are involved in the process, one recruiting officer using the website may be a crucial contradiction. This contradiction seems hard to solve since it is mainly caused by the company. Nevertheless, the presentation of information of the website may be changed according to the preferences of the different people at the company, but this may introduce new contradictions.

Action \#7-9: These actions do not seem to cause problems as long as an (email) address of the students is available. The job interview and the employment do not involve the website in any significant way.

\section{Step 3: Follow-up}

When the walkthroughs for each identified use situation are finished, the problem solving begins by listing immediate solutions (identified in step 2) and deciding solutions to the not yet solved problems (as in figure 5). Since this example is a condensed version to illustrate the flow of WAW, we will not go into details with the exact identified problems and solutions, but as an example of how solutions are decided, consider the problem in action \#6 of use situation \#1.

Use situation \#1 is important because it is based on a necessary use. This means that this action cannot be ignored, neither can we do major modifications of the requirement specification. Thus, we have to change the design of the website in order to eliminate the problem or possibly verify the genuineness of the problem by an empirical investigation. Follow-up solutions are recorded in a dedicated column of figure 5.

INSERT FIG 5: Summary of actions, problems and solutions of use situation \#1

When all the solutions are decided and listed for each use situation, WAW is finished and the re-design of the website may begin.

\section{EVALUATION OF WAW}

The construction of the WAW demonstrates that it is possible to base a walkthrough method on activity theory. To make sure that it is possible for others than the authors to use the method in practice, we have conducted informal evaluations with various users. Our greatest concern has been whether or not the method is usable. In other words: is WAW usable for usability inspectors (or others) to inspect websites, and does WAW identify usability problems with and in connection with websites? Furthermore, we wanted to examine the effectiveness and efficiency of the WAW. Since reliable measurements of the effectiveness and efficiency of the method would require an extensive amount of data and probably still be inexact, we will only sum up the tendencies based on our current experiences.

To evaluate WAW we performed two different studies with inspectors who had never used the WAW method before. In both studies only parts of the websites were analyzed. 
The first study was an inspection of a website under development by four of the developers of the website. The developers of the website are also graduate students in computer science with a comprehensive knowledge about websites and HCI, as well as some understanding of activity theory. The purposes of this study were to see if the method was usable for inspectors with a fairly broad theoretical and professional background; to see if WAW was effective in identifying relevant problems; and in general to get a sense of the efficiency and effectiveness of the method.

The procedure was that a team of two developers cooperatively prepared and performed a WAW of the website they were currently developing. The developers were asked to think out loud while performing the WAW. The session was recorded on video and subsequently analyzed. We were particularly interested in complications and difficulties with using WAW, as well as time consumption alongside the identified problems. We conducted this procedure with two different teams.

\section{The student study}

The second study was carried out as part of a course on web design taught by one of the authors. The students were academics, typically with a MA degree, wanting to become IT-professionals; they typically had some knowledge about usability and no knowledge on activity theory.

The procedure was that the student had a brief introduction to the WAW and then they were asked to perform the WAW on a website they were either developing or redesigning. They had a few hours to the task and were thus asked to focus on a sub-part of the website.

The main focus of this study was to find out if it was possible for people with very little knowledge about web usability or activity theory to perform the WAW and if the method enabled them to identify usability problems.

\section{Results of the two studies}

Is WAW usable, and does it identify usability problems? The two studies indicate that the WAW is usable for early assessment of websites, and that it identifies relevant problems. In both studies the inspectors were able to inspect websites using the method, though with some difficulties. The students consistently had more difficulties than the developers. In general, the problems they experienced using WAW were related to understanding activity theory in general and the contextualization in particular; and they had problems understanding the procedure for performing the WAW.

Due to the lack of resources most of the problems identified in the developer study were not corrected in the respective websites. This gave us an opportunity to assess the relevance of the problems identified in the WAW analysis of the developer study, by comparing them to the problems reported by users in later, as well as earlier error reports. The general picture is that there is a large intersection between the problems identified with the WAW and the error reports. Furthermore, some of the identified problems involve aspects of usability that standard approaches might not identify - e.g. the need for a real-life introduction workshop with hands on exercises, online conversion of Word-documents into RTF-documents

p91 to support cooperation across software platforms, or the need for a FAQ on printing problems when the user has not transferred money into his/hers printing account.

A somewhat surprising observation was that the inspectors in the developer study spontaneously used the contextualization as a thinking tool to invoke and support a general discussion and clarification of the use of the website. We see it as a strength of the method that it "invites" to such an open ended application, even though our explicit intention with the method is to transcend the tendency to use activity theory merely as "a set of glasses". 


\section{Efficiency of WAW}

At first sight the WAW may seem overly complicated and it could be suspected that it would be very time consuming to perform it. However, both the two evaluation studies, and our own experience indicate that it is not that critical.

The list below provides a rough estimate of the efficiency of the WAW based on the two studies and our own experience.

- Step 1.1: Identifying uses did not involve any problems and naturally depends on the number of uses the website must support. If a reasonable requirement specification is present, this step takes at most 2 hours.

- Step 1.2: Contextualization done by inexperienced users of WAW usually takes about 1.5-2.5 hours depending on the complexity of the website, and the quality of the requirement specification. A contextualization is usually done only once, thus it is fair to estimate that the experienced inspector will use less than 2 hours for this step.

- Steps 1.3, 2 and 3: Identifying the activity system containing the use situation, the problems and the solutions for each identified use typically lasts about half an hour. An experienced inspector might do this quicker.

To sum up: a reasonable time schedule for the experienced WAW-inspector to inspect a website would include 1 hour to identify uses, 2 hours to contextualize the uses and 20-30 minutes for each use to identify problems and solutions. This means that it is possible to inspect an "average" website in one day of course depending on the number of different uses and users/target groups and the complexity of the website.

\section{CONCLUSIONS}

The WAW illustrates that it is indeed possible to build practical tools for early usability inspection based on activity theory. Our studies of WAW in use suggest that it is possible to spot problems beyond the level targeted by traditional methods like the cognitive walkthrough. Moreover, the evaluation of the method indicates that it is both cheap and fast, making it possible for one or two inspectors to analyze a website in a few hours. Compared to established analytic methods like the Cognitive Walkthrough [13], WAW gives the inspector stronger means for predicting whether or not the users will be able to make sense of the website in the context of their specific situations. The strength of WAW compared to e.g. the cognitive walkthrough is that WAW has explicit support for considering the entire context of use based on the human activity framework. It is an open question, however, to which extend it would be possible to present the method without a thorough introduction to the theoretical underpinning in a way similar to what has been done with the cognitive walkthrough. Our observations so far indicate that the theoretical basis is important and manageable for the various users of the method. The evaluations of WAW showed that the method is most likely to be successful if inspectors have some knowledge of the basic concepts of activity theory. In the student study those who had read an early draft of the present introduction in addition to the step-by-step description of the method were able to perform the walkthrough by themselves. Our initial worry was that the complexity of the WAW and its dependence of the inspector's understanding of activity theory could be a limiting factor. However, our evaluations indicate that this might not be an insuperable problem.

It might be argued that the WAW is only loosely based on activity theory, and that a more careful use of the theoretical basis would have yielded a stronger method. However, our initial motivation has been that activity theorists aught to become more committed to the production of practical instruments for ITdesign, rather than merely providing great analyses of IT use and design. With respect to web usability in general, however, our experiments with the WAW indicate that web usability methods would benefit from a stronger theoretical underpinning 
Future work with WAW will include the construction of a formalized inspector guide and the application of the method in a large-scale website development project. Another step further could be to develop assessment methods more rigidly derived from activity theory.

\section{ACKNOWLEDGMENTS}

We owe great thanks to the developers Christian, Bent, Allan and Jacob and the students at NetJob for acting as inspectors in our studies. Also thanks to Kirsten Foot, Marianne Graves Petersen and Susanne Bødker for fruitful comments, and to Marianne Iversen and Ann Mølhave for proof reading.

\section{REFERENCES}

1. Bannon, L. \& Bødker, S. (1991), Beyond the Interface: Encountering Artifacts in Use, in Carroll, John M. (ed.) Designing Interaction, Cambridge: Cambridge University Press.

2. Bannon, L. J. \& Kuutti, K. (1993). Searching for Unity among Diversity: Exploring the "Interface" Concept, In Ashlund, Stacey et al. (eds.), INTERCHI '93: Conference on Human Factors in Computing Systems INTERACT '93 and CHI '93 Bridges Between Worlds. New York, N.Y.: ACM Press.

3. Bertelsen, O. W. \& Bødker, S. (2003). Activity Theory. In Carroll , J.M. (ed.). HCI Models, Theories, and Frameworks: Toward an Interdisciplinary Science. Morgan Kaufman Publishers.

4. Bertelsen, O. W. (1996). Contradictions in the Festival Project - Activity systems, obstacles and dynamic forces in design. In Dahlbom, Ljungberg, Nuldén, Simon, Sørensen \& Stage (eds.). Proceedings of the 19th. Information systems Research seminar in Scandinavia, (IRIS 19), 10-13 August 1996, at Lökeberg, Sweden. pp.597-612.

5. Bødker, S. (1991). Through the Interface: A Human Activity Approach to User Interface Design. Hillsdale, New Jersey: Lawrence Erlbaum Associates.

6. Bødker, S. (1996). Applying Activity Theory to Video Analysis: How to Make Sense of Video Data in Human-Computer Interaction. In B. Nardi, ed., Context and Consciousness - Activity Theory and Human-Computer Interaction. Cambridge: The MIT Press.

7. Engeström, Y. (1987) Learning by Expanding: an activity - theoretical approach to developmental research. Helsinki: Orienta-Konsultit Oy.

8. Engeström, Y. (1993). Developmental studies of work as a testbench of activity theory: The case of primary care medical practice. In S. Chaiklin \& J. Lave (eds.). Understanding practice - Perspectives on activity and context. Cambridge University Press.

9. Jacobsen, N. E., M. Hertzum and B. E. John (1998).The evaluator effect in usability tests. In Proceedings of the conference on CHI 98 summary: human factors in computing systems, 1998, 255-556

10. Kaptelinin, Victor (1996). Activity Theory: Implications for Human-Computer Interaction. In B. Nardi, ed., Context and Consciousness - Activity Theory and Human-Computer Interaction. Cambridge: The MIT Press.

11. Kaptelinin, V., Nardi, B. \& Macaulay, C. (1999). The Activity Checklist: A Tool for Representing the "Space" of Context. In Interactions... July + August 1999.

12. Leontjev, A. N. (1978). Activity, consciousness, and personality, Engelwood Cliffs NJ: Prentice Hall.

13. Lewis C. (1997). Cognitive Walkthroughs, In Helander, M.G et al. (eds.). Handbook of HumanComputer Interaction, (pp. 717-732). Completely Revised Edition. Elsevier

14. Nielsen, J. \& R. Molich (1990). Heuristic evaluation of user interfaces. In Proceedings of CHI 90: human factors in computing systems, Seattle, WA April 1-5. pp 249-256, New York ACM/SIGCHI.

15. Shneiderman, B (1998). Chapter 16. In Designing the User Interface: Strategies for Effective Human-Computer Interaction, 3rd. Edition, Addison-Wesley, 1998 


\section{BIOGRAPHICAL NOTES}

Olav W. Bertelsen is an associate professor of human-computer interaction and systems development at the Department of Computer Science, University of Aarhus. Olav has been teaching human-computer interaction at the interdisciplinary multimedia education since 1998. His $\mathrm{PhD}$ thesis, Elements of a Theory of Design Artefacts, was an attempt to give a systematic account, based on activity theory, on the tools, methods, techniques etc. mediating the design of computer artefacts. Actual research interests include common information spaces; activity theory-based methods and techniques in human-computer interaction; and a reformation of human-computer interaction as an aesthetic discipline based in dialectical materialism.

Mikkel Godsk is a teacher, web-editor and a student of information technology and multimedia science at the IT University West, University of Aarhus, and is currently writing his master's thesis in the field of human-computer interaction on an activity theory based method for website analysis. Mikkel is trained as New Media Manager and has since 1998 studied and worked with various aspects of humancomputer interaction. Furthermore, Mikkel has worked as web-designer, web-editor, web-master and usability inspector, and developed knowledge about practical development and test of websites. Recently, he has been teaching web usability at retraining courses, and is currently teaching a course on writing for the web at the University of Aarhus. 


\title{
FIGURES
}

\author{
1. DESCRIBING AND SITUATING THE WEBSITE AND ITS USES \\ 1.1 IDENTIFYING THE USES \\ - What necessary uses must the website support? \\ - What frequent uses must the website support? \\ - What extra-ordinary uses must the website support? \\ - What other uses must the website support?

\subsection{CONTEXTUALIZATION} \\ 1.2.1 The website and its future use: \\ - What is the purpose of the website? \\ - What characterizes the users/target groups? \\ - What characterizes the originators? \\ - What characterizes the design? \\ 1.2.2 Situating the website and its uses: \\ - Is it a versioning or a further development, redesign or new website? \\ - $\quad$ Experiences with the existing website (if any)? \\ - Reason for redesign or further development? \\ - Influence on existing use/work procedures? \\ - $\quad$ Are there corresponding websites? What are their characteristics? Experiences with these websites. \\ 1.2.3 Mediation: \\ - What kinds of mediation will the website support? System, tool and/or medium? \\ - What consequences does it have? \\ - $\quad$ Are there any "web rare" mediations? \\ - What consequences does it have? \\ 1.2.4 Internalization and Externalization: \\ - What kinds of internalization and externalization must the website support? \\ - Must the users learn or express something with the website? \\ - Do users cooperate/communicate via the website? \\ 1.2.5 Network of activities: \\ - In what other activities is the website included (look for motives)? \\ - How do these activities relate to the considered activities? \\ 1.2.6 Distribution: \\ For each user/target group ask: \\ - Will this target group mainly use the website with the website as context? \\ - If yes, describe the rules, community and division of labor of the website context. \\ - Will this target group mainly use the website with the internet in general as context? \\ - If yes, describe the rules, community and division of labor of the internet context. \\ - Will this target group mainly use the website within a local context? \\ - If yes, describe the rules, community and division of labor of the local context. \\ (This may require special tools from other sciences). \\ 1.3 IDENTIFYING POSSIBLE USE SITUATIONS \\ For each specified use ask: \\ What possible use situations may the specified use be a part of: \\ - Why does <the user/target group> use the website for/to <use > ? (What is the motive?) \\ Engeström's components for the specific activity (defining the use situations): \\ - Which actions is the use situation realized through? \\ - What is the object, subject, outcome, instrument, rules, community and division of labor?

\section{IDENTIFYING PROBLEMS}

The specified use situations are inspected one by one, action by action

For each use situation:

Immediate contradictions:

- Does the use situation have any immediate contradictions?

- Is there an immediate solution (to eliminate the contradiction)?

- If yes, make a note of the solution.

- If no, make a note of the contradiction, the use, kind of use (e.g. "necessary") and the current action.

For each action in the use situation:

- Have any components changed?

- If no, go to the next action.

- If yes, have there arisen any conflicts?

- If no, go to the next action.

- If yes, note the current action and identify contradictions and solutions as shown above.

3. FOLLOW-UP

For each identified, and not yet solved (in step 2), problem consider:

- Is it possible to ignore the problem?

- Is it possible to solve the problem by changing the design of the website?

- Is it possible to prevent the problem by modifying the "requirement specifications" and how?

- Is it an actual problem (this requires empirical investigation)?

Figure 1. The Website Activity Walkthrough (WAW). 


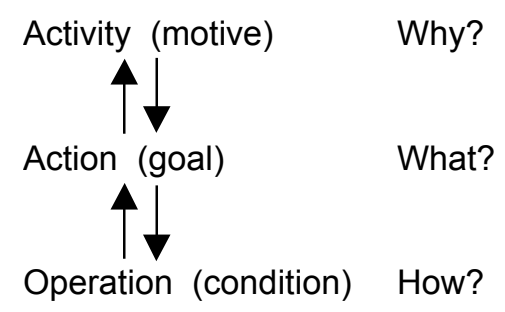

Figure 2: The hierarchical structure of activity. 


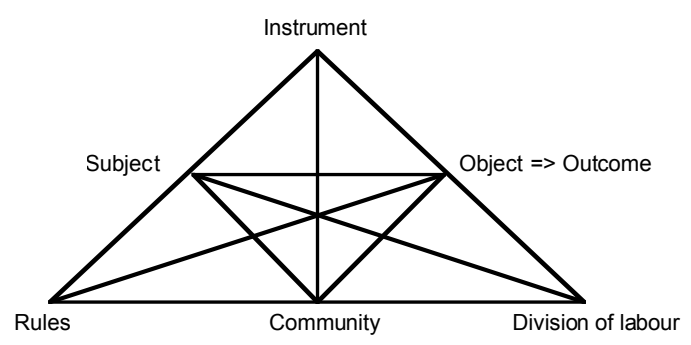

Figure 3: The systemic structure of human activity. Adopted from Engeström [7 p.78]. 


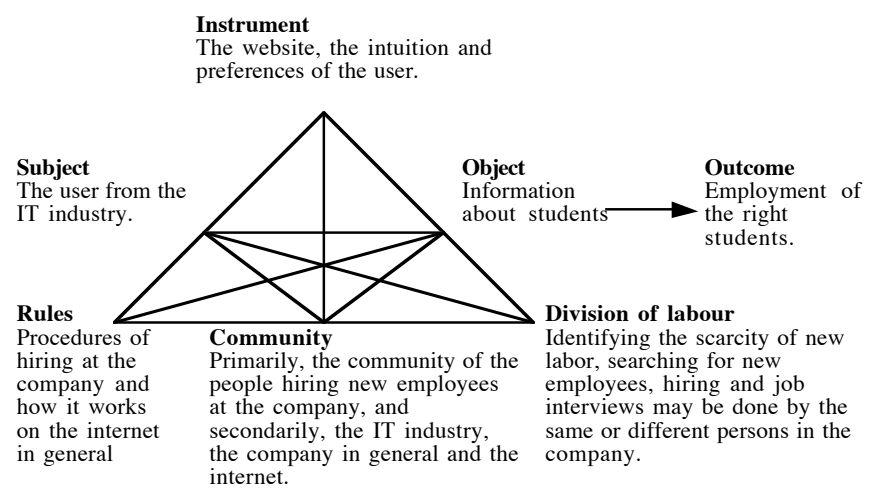

Figure 4: The activity system containing use situation \#1 involving the use of the website. 


\begin{tabular}{|c|c|c|c|c|}
\hline $\begin{array}{l}\text { Use situation } \\
\text { (importance of } \\
\text { use) }\end{array}$ & Action & Problem & Solution & Follow-up solution \\
\hline \multirow[t]{4}{*}{$\begin{array}{l}\text { \#1 } \\
\text { (necessary) }\end{array}$} & $\begin{array}{l}\text { Immediate } \\
\text { contradiction } \\
\text { of the use } \\
\text { situation }\end{array}$ & $\begin{array}{l}\text { Contradiction between the proce- } \\
\text { dures of hiring (rules) and the web- } \\
\text { site; since the company usually em- } \\
\text { ploy labor through announcements - } \\
\text { no headhunting! }\end{array}$ & $\begin{array}{l}\text { To change the appeal of the web- } \\
\text { site or letting the companies an- } \\
\text { nounce job openings. }\end{array}$ & No follow-up solution. \\
\hline & $\begin{array}{l}\text { \# 4: } \\
\text { Searching the } \\
\text { website }\end{array}$ & $\begin{array}{l}\text { How the information is structured on } \\
\text { the website in relation to how infor- } \\
\text { mation about personal qualifications } \\
\text { is structured in the industry. (possible } \\
\text { problem, needs verification) }\end{array}$ & $\begin{array}{l}\text { (To structure the information about } \\
\text { the personal qualifications of the } \\
\text { students as in the industry.) }\end{array}$ & $\begin{array}{l}\text { (It might be possible to } \\
\text { ignore this problem since } \\
\text { the industry should know } \\
\text { that the website is not a } \\
\text { recruitment site, or pre- } \\
\text { venting the problem by } \\
\text { modifying the requirement } \\
\text { specification.) }\end{array}$ \\
\hline & $\begin{array}{l}\text { \# 5: } \\
\text { Acquiring } \\
\text { information } \\
\text { about stu- } \\
\text { dents }\end{array}$ & $\begin{array}{l}\text { A contradiction between the data } \\
\text { about the students on the website } \\
\text { (object) and the usual design of a job } \\
\text { proposal or what the user wants to } \\
\text { know (subject). }\end{array}$ & $\begin{array}{l}\text { To either add more information } \\
\text { about the students (but this may } \\
\text { cause other contradictions to other } \\
\text { specifications of the website) or add } \\
\text { an email address, so the user may } \\
\text { contact the student and obtain the } \\
\text { needed information. }\end{array}$ & No follow-up solution. \\
\hline & $\begin{array}{l}\text { \# 6: } \\
\text { Selecting the } \\
\text { students }\end{array}$ & $\begin{array}{l}\text { A contradiction between how different } \\
\text { people usually are involved in hiring } \\
\text { new employees (division of labor) and } \\
\text { what instruments the website offers } \\
\text { (instrument). }\end{array}$ & $\begin{array}{l}\text { The presentation of information of } \\
\text { the website may be changed ac- } \\
\text { cording to the preferences of the } \\
\text { different people at the company. } \\
\text { May not solve the problem. }\end{array}$ & $\begin{array}{l}\text { Solving the problem by } \\
\text { changing the design of the } \\
\text { website, or verifying the } \\
\text { genuineness of the prob- } \\
\text { lem by an empirical inves- } \\
\text { tigation. }\end{array}$ \\
\hline
\end{tabular}

Figure 5: Summary of actions, problems and solutions of use situation \#1. 